\title{
Wyndham Lewis y su recepción en España: etapas editoriales y traducciones
}

\author{
Yolanda Morató \\ Universidad de León \\ ymora@unileon.es
}

\begin{abstract}
Resumen: El caso de la ausencia de traducciones al español de obras completas del escritor Wyndham Lewis durante casi un siglo es uno de los más significativos del panorama literario español. La primera traducción no aparece hasta 2005 (Dobles fondos, trad. M. Temprano). Tras el fructífero periodo editorial en que se revitalizaron muchas de las traducciones que habían sido censuradas durante el periodo franquista ninguno de sus títulos tuvo cabida. Este artículo traza distintas etapas para analizar si Lewis fue un autor claramente censurado o si, por el contrario, fue víctima de una serie de factores sin aparente conexión que le hicieron caer en el olvido durante décadas, a pesar de su importante contribución como artista y escritor.
\end{abstract}

Palabras clave: modernism; traducción; censura; Wyndham Lewis; fascismo.

\begin{abstract}
Wyndham Lewis's works remained untranslated into Spanish for almost a century, being one of the most peculiar cases in the Spanish literary world. The first complete translation was not published until 2005 (Dobles fondos, trans. M. Temprano). Even if many censored translations during Franco times were revised and published thanks to the flourishing period in the Spanish publishing sector in the first years of democracy, not a single work by Lewis was chosen. This article analyses his reception throughout different stages of the $20^{\text {th }}$ century to analyse whether he was clearly censored in Spain or if, on the contrary, he was the victim of certain disconnected factors that made him fall into oblivion, despite his important contribution as an artist and a writer.
\end{abstract}

Keywords: modernism; translation; censorship; Wyndham Lewis; fascism. riales y traducciones". Quaderns de Filologia: Estudis Literaris XX: 183-197. doi: $10.7203 /$ qdfed.20.7536 



\section{Un modernista en la sombra o el censor censurado}

Si bien es cierto que en España sigue siendo relativamente desconocido, Wyndham Lewis ${ }^{1}$ (1882-1957), escritor y pintor estrechamente relacionado con Eliot, Pound y Joyce, supo hacerse un nombre en unas décadas muy fructíferas para la literatura en lengua inglesa. Antes de convertirse en el implacable crítico que diseccionó la sociedad con sus duras novelas -la mayoría de ellas son sátiras que pueden leerse como cáusticos romans à clef de las ciudades en que vivió (París, Londres, Boston y Toronto) - y sus dos volúmenes de memorias, Estallidos y bombardeos (Blasting and bombardiering, 1937) y Rude Assignment (1950), Lewis fue pintor, publicó relatos, novelas, poemas y hasta dos obras de teatro, editó tres revistas y logró convertirse en un cronista cultural de mucho calado en su época ${ }^{2}$. A pesar de su prolífica contribución al modernismo anglo-norteamericano, la obra de Lewis ha sufrido durante casi un siglo un considerable vacío en España, tanto en su vertiente de ficción como de no ficción. Su obra pictórica, por el contrario, ha experimentado ahora una revalorización provocada, principalmente, por las exposiciones que se analizarán en la última sección de este artículo.

Como una gran parte de los escritores que integran el movimiento literario en lengua inglesa conocido con el nombre de Modernism, Lewis no nació en el país en el que alcanzaría fama como pintor, editor, narrador y ensayista. Después de una serie de viajes a Alemania, Francia y España durante los primeros años del siglo XX, se instaló en Londres y publicó su primer relato en la revista The English Review, que por entonces dirigía Ford Madox Hueffer (quien, por temor a la censura que podría sufrir por su apellido alemán, pasó a llamarse poco más tarde Ford Madox Ford). A pesar de un prometedor comienzo, los años de la preguerra no fueron tan fructíferos en lo literario como en lo artístico para Lewis. Tras ir encadenando experiencias en asociacio-

\footnotetext{
${ }^{1}$ En las aulas universitarias españolas su nombre apenas se cita, pues no está incluido en el canon del Modernismo anglonorteamericano y, hasta hace una década, sus novelas eran difíciles de conseguir.

${ }^{2}$ Como narra con cierta burla el propio Lewis en un capítulo, "El Primer Ministro y yo, 1914", de su primera autobiografía, Estallidos y bombardeos (1937; trad. 2008), fue invitado al número 10 de Downing Street, donde Asquith le preguntó discretamente sobre sus actividades, como si de un espía se tratara.
} 
nes de pintores como el London Group, el Camden Town Group y los Omega Workshops, Lewis y un grupo de artistas que se marcharon con él de los talleres liderados por Roger Fry se constituyeron como parte de un proyecto que duraría tan solo unos meses, el Rebel Art Centre. A partir de aquí, y con el apoyo incondicional de Ezra Pound, nació el Vorticismo, un movimiento con mayor importancia que la que se le ha adjudicado tradicionalmente. Su revista, Blast, lanzó tan solo dos números, pero fueron suficientes para llamar la atención de los círculos culturales de la época.

Para localizar el primer caso de censura que experimentó Lewis, en su labor de editor, solo ha de consultarse el número 1 de Blast, donde el poema "Fratres Minores" (1914: 48), de Pound, incluye tres versos tachados con gruesos trazos negros que, con todo, no son lo suficientemente opacos y permiten que pueda leerse lo siguiente:

With mind still hovering about their testicles [verso 1] That the twitching of three abdominal nerves [verso 6] Is incapable of producing a lasting Nirvana. [verso 7]

Rose (1963: 67) señala que Lewis, como editor, tenía "the naïf determination to have no "words ending in -Uck, -Unt, and -Ugger'" pero acabó publicando un primer número en el que aparecía un poema de Pound que recibió censura parcial, al tiempo que excluía los poemas de Eliot, que colaboró en el segundo número de la revista. En una carta a Pound de 1915, le comentó que Eliot le había informado de que "he had written a lot of filthy sexual verse, which, if he sends it, I shall hang in the W.C." (Rose, 1963: 68) ${ }^{3}$. Tan solo tres años más tarde, sería su propia obra la que sufriría censura, aunque, en esta ocasión, las consecuencias fueron más graves. En 1917, gracias a las labores de Pound como corresponsal editorial, el autor había colaborado en el número de octubre de The Little Review con el relato "Cantleman's Spring-Mate".

\footnotetext{
${ }^{3}$ Aunque tuvo que pasar casi un siglo, acabaron publicándose en 1996 con el título Inventions of the March Hare: Poems 1909-1917. En una carta fechada el 21 de septiembre de 1922, Eliot le pedía a John Quinn, a quien se los había vendido: "I beg you fervently to keep them to yourself and see that they are never printed" (en Gardner, 1972: 7). El escándalo tras la publicación de este cuaderno inédito fue considerable y generó un interesante debate en The New York Times. Lyall (1996) señala las conexiones entre Eliot y otros miembros de su generación por el uso del lenguaje sexista y antisemita que predomina en estos poemas.
} 
El número fue confiscado por la oficina postal en las aduanas estadounidenses por obscenidad ${ }^{4}$.

El impacto del escándalo provocado por dicho relato no debe pasarse por alto, pues fue, entre otras cosas, la causa del retraso en la publicación de los primeros capítulos del Ulises de Joyce. Pound informó al escritor irlandés de que el número de noviembre había sido confiscado debido al relato de Lewis en el número anterior, advirtiéndole de que no era el momento más propicio para promover el tipo de ficción que escribía uno de sus tres apadrinados ${ }^{5}$. Como se anunciaba en el subtítulo, la revista no se plegaba al gusto del público ("making no compromise with the public taste"), pero sus editoras nada podían hacer para esquivar los efectos de la censura una vez publicadas las polémicas colaboraciones de sus autores. Estos incidentes no serían sino los primeros de una larga lista. En represalia a las sátiras que escribía, Lewis tuvo numerosos problemas con diversos editores y autores, viéndose obligado a contratar a abogados para solucionarlos. En 1938, el pintor Augustus John dimitió de su puesto en la Royal Academy en señal de protesta ante el rechazo de uno de los mejores cuadros de Lewis, el retrato de T. S. Eliot.

\section{Etapas durante un siglo}

Desde la publicación en Londres de la revista Blast (1914-1915) hasta la aparición de su obra póstuma Mrs. Duke’s Millions (1977), nunca se publicó en España ninguna de las obras de Lewis, a pesar de que superan los cuarenta volúmenes, algunos de los cuales se editaron en otros mercados como el francés o el italiano, donde se traduce menos que en España $^{6}$.

\footnotetext{
${ }^{4}$ Entre los más de 5000 libros que prohibió el Irish Board of Censorship entre 1929 y 1967, también estaba la obra de Lewis (Moi, 2009: 58).

${ }^{5}$ Durante los años de la Primera Guerra Mundial, Pound funcionó de manera informal como agente de Eliot, Joyce y Lewis, por lo que parece más que apropiada la etiqueta de "The Men of 1914" con la que Lewis describió a este grupo de escritores entre los que él mismo se incluía. Forrest Read (1967) describe en detalle todos los problemas con la publicación por entregas de los capítulos de Ulysses tras la censura de "Cantleman's Spring Mate".

${ }^{6}$ Junto a Bradford Morrow, Bernard Lafourcade catalogó toda la producción de y sobre Lewis hasta 1978. Además, Lafourcade tradujo al francés las siguientes obras de Lewis: "Cantleman's Spring-Mate" (París, 1968), Tarr, 1928 (París, 1970), The Revenge for Love (Lausana, 1980) y The Wild Body (en colaboración, Lausana, 1980).
} 
Para analizar las diferentes fases que ha atravesado su obra en lengua española, se ofrece a continuación una clasificación tentativa de las cuatro etapas fundamentales en las que puede dividirse la recepción de su obra (o la ausencia de esta) en España.

\subsection{Etapa de desconocimiento (1914-1957)}

No deja de parecer sorprendente que un movimiento que ha sido juzgado como la continuación del Futurismo italiano no llegase a España, ni en los mismos plazos ni con la misma intensidad. Apoyados por las revistas ultraístas, las compilaciones y traducciones, y los estudios de Ramón Gómez de la Serna, los movimientos europeos de vanguardia se siguieron con mucho interés en España. No obstante, ni en Literaturas Europeas de Vanguardia (1925), de Guillermo de Torre, ni en Ismos (1931), tan fecundo en movimientos de vanguardia que algunos se los inventó el propio Gómez de la Serna, aparecen siquiera citados Lewis o el Vorticismo. Tendrá que ser en una reedición muy ampliada del libro de Guillermo de Torre, Historia de las Literaturas Europeas de Vanguardia (1965; un libro distinto de aquel del que parcialmente toma su título), donde por fin se den unas pinceladas difusas sobre la contribución lewisiana al panorama internacional. No obstante, como se verá en la segunda etapa que se analiza, los numerosos errores de este texto vuelven a poner de manifiesto el desconocimiento y la confusión general sobre el legado de Lewis.

Ni Antonio de Marichalar ni ninguno de los autores que publicaban sobre escritores en lengua inglesa parecían saber acerca del trabajo de Lewis, a pesar del impacto que tuvieron los dos números de la revista Blast, pues no hay que olvidar que Eliot publicó en ella sus primeros poemas y Ford incluyó un avance de El buen soldado. ${ }^{7}$ Las traducciones del resto de los integrantes de "The Men of 1914" demuestran que Lewis sufrió un evidente vacío. De lo contrario, obsérvese la fecha de la traducción del El artista adolescente de Joyce que Dámaso Alonso realizó bajo el pseudónimo de Alfonso Donado para Biblioteca Nueva

\footnotetext{
${ }^{7}$ El título de su colaboración en el primer número de Blast, "The saddest story", se convertirá en la primera frase con la que abre Ford su novela: "Esta es la historia más triste...”. Salvo por leves cambios, la revista reproduce en sus páginas los que más tarde serán los primeros cuatro capítulos de esta obra.
} 
(en 1926); o la de Tierra Baldía a cargo de Ángel Flores para Editorial Cervantes (en 1930). Pound tuvo que esperar algo más, pues Vázquez Amaral publicó Los cantares de Pisa en la UNAM en 1956; en España aparecieron en 1960, gracias a Jesús Pardo, como Los cantos pisanos, en la colección Adonais de Ediciones Rialp. No obstante, no puede equipararse de modo alguno a la ausencia de Lewis del panorama editorial español, en cualquiera de los géneros en los que destacó.

\subsection{Etapa de censura (1958-1975)}

Desde la breve entrada necrológica que la Enciclopedia Espasa dedica a Lewis, donde aparece entre los autores fallecidos en 1957, hasta la publicación de Historia de las Literaturas Europeas de Vanguardia de Torre transcurren ocho años. No obstante, lejos de despertar interés en España, la figura de Lewis se distorsiona algo más. En las únicas dos páginas que Torre le dedica al movimiento vorticista ${ }^{8}$, los errores sobre su producción narrativa son numerosísimos.

Entre las incorrecciones más evidentes está la clasificación del primer número de la revista Blast (1914) como "una hoja tamaño de sábana" (474) en lugar de describir una revista que contaba con 160 páginas. Por ello, Torre concluyó erróneamente que el segundo número de Blast (1915) era, en realidad, el primero. En el uso de la palabra sábana se intuye con facilidad que Torre leyó en inglés la información sobre la revista, pues sheet, además de página u hoja (acepciones que el autor no contempló cuando muy posiblemente consultó el término en un diccionario), tiene como primer equivalente el de sábana. Además, le atribuyó a Lewis la revista en la que trabajó Eliot, The Egoist (475), confundiéndola, quizás, con la tercera que editó Lewis, The Enemy, desde 1927 a 1929.

En las escasas páginas que Torre le dedicó al movimiento vorticista, lo catalogó como una expresión del autor "sin trascendencia en otros" (474) y, aunque afirmó acertadamente que Lewis "se incluye en la generación de 1914" (475), parecía desconocer que fue el propio Lewis quien acuñó el nombre del grupo generacional y, por tanto, quien aglutinó a Pound, Eliot y Joyce bajo dicha clasificación.

\footnotetext{
${ }^{8}$ En realidad, este apartado dedicado al Vorticismo tiene cierto carácter anecdótico, pues se trata de una pequeña sección dentro de un capítulo dedicado al Imagismo.
} 
Miguel Abellán (1980: 88), sociólogo y pionero en el análisis de los archivos, enumeró los cuatro pilares con mayor asiento en los informes de censura: la moral sexual, las ideas políticas, el lenguaje indecoroso y la religión. Teniendo en cuenta cualquiera de los cuatro, los libros de Lewis difícilmente habrían quedado impunes. Como precisa Torre, era un "pintor, escritor, propagandista tan admirable en algunos aspectos como vituperable en otros" (474). A falta de expedientes e informes de censura, solo queda aventurar la suerte que habría corrido su obra en España, considerando todos los problemas legales que le causaron sus novelas en Inglaterra, descritos en detalle por Edwards (2000).

Otros autores como Céline, con su ya clásico Viaje al fin de la noche, tampoco salieron airosos durante esta etapa. En el caso del escritor francés, su traducción al español apareció en Buenos Aires en 1945 gracias a la editorial Siglo XX y al traductor Armando Bazán, pero no llegó a España hasta 1973, año en que la publicó Planeta. El temor a posibles represalias, unido al desinterés general en introducir en el mercado la obra de autores con visiones intelectualizadas que pudieran catalogarse de amorales, los alejó de las editoriales españolas durante el franquismo. "No ha habido en toda la historia de Inglaterra ninguna publicación más intelectual que Blast", afirmó el propio Lewis (2008: 115) en su primera autobiografía.

\subsection{Etapa de omisión (1976-1993)}

Que existe un prejuicio hacia la obra de Lewis ha sido constatado por los propios estudiosos del modernismo británico. Brighton (1996: 169170) explicaba que

The distaste for Lewis is a complex symptom, a meld of both aesthetic and ideological assumptions. [...] [h] e questioned or opposed some of the fundamental assumptions of establishment culture, he was a class traitor, he $[\mathrm{sic}]$ an anti-progressive and rejected humanist aestheticism. From the point of view of the British cultural establishment the distaste for Lewis is well founded.

También Cunchillos (2003: 24) señaló que en las últimas décadas del siglo XX se habían "realizado estudios sobre P. W. Lewis que han puesto de manifiesto cómo las primeras críticas que recibió fueron política- 
mente sesgadas y literariamente desatinadas". El rechazo hacia su obra ha sido, por tanto, incontestable.

Con la entrada en una etapa de transición encaminada a constituir formalmente un gobierno democrático en España, ningún editor español pareció atreverse a publicar al escritor que en 1931 había presentado a Hitler como "un hombre de paz". Lo curioso es que la publicación de Hitler (1931), una obra por la que Lewis se disculpó en distintas ocasiones a lo largo de su vida y en diferentes libros, fue prohibida por el propio líder nazi tras realizarse una traducción al alemán. Al contrario de lo que pudiera pensarse, el ensayo defendía las políticas alemanas como medio imprescindible para evitar una guerra e instaurar la paz en Europa ${ }^{9}$.

En España, ninguna de las obras de Lewis se publicó durante las décadas de los ochenta y noventa. En este caso y periodo, su ausencia en los catálogos editoriales ya no puede achacarse al desconocimiento, pues la revista Poesía le había dedicado una extensa sección al movimiento vorticista en 1980, además de un exhaustivo estudio a la figura del autor, firmado por Kevin Power. Los lectores de Poesía eran numerosos y la publicación se había convertido en una guía de referencia entre editores. Power, además, había publicado The Relationship of Ultraism \& Vorticism with Futurist Practice \& Theory, convirtiéndose así en el primer estudioso de Lewis en el ámbito académico español.

\subsection{Etapa de florecimiento (1994-actualidad)}

La labor investigadora sobre la vida y obra de Lewis, llevada a cabo en el seno de la Universidad, es, sin duda, uno de los desencadenantes de la revitalización del autor en nuestro país. Tres décadas más tarde del estudio de Power, el proyecto de investigación "La estética modernista a través de un prisma radical: La visión satírica de Percy Wyndham Lewis y su continuidad" (BFF2002-02842), dirigido por Carmelo Cunchillos, logró aglutinar a cinco profesores universitarios españoles (Cunchillos, Asensio, Hernáez, Terrazas y Villar) y dos británicos (Munton y Smith) en torno a los distintos aspectos de la figura de Lewis. Si nos centra-

\footnotetext{
${ }^{9}$ Lewis no supo ver las consecuencias que acarrearían unas políticas de esta magnitud y simplificó los odios raciales, interpretándolos como simples prejuicios de la sociedad de la época.
} 
mos en las tesis doctorales que estudian en exclusiva la obra de Lewis, podrá comprobarse que hasta 2006, año conmemorativo de la Guerra Civil española en que se revisó la contribución de numerosos escritores ingleses a los temas españoles, se habían presentado únicamente dos (frente a las veinte defendidas en Reino Unido entre 1973 y 2006) ${ }^{10}$. Los dos trabajos de investigación españoles analizan la producción escrita de Lewis (que cuenta con más de cuarenta títulos), centrándose en algunas novelas con la profundidad que permite un trabajo de estas características bajo una perspectiva semiótica ${ }^{11}$.

En 1996, Díaz Cuesta publica "Percy Wyndham Lewis: Writer, Painter, Artist", un artículo en el que trata las distintas facetas de Lewis, artista y escritor, y lo desmarca de D. B. Wyndham Lewis, que con su estudio sobre Goya y sus escritos humorísticos produjo (y sigue produciendo esporádicamente) ciertas confusiones en manuales de carácter generalista $^{12}$. En la XXVI edición del congreso de AEDEAN, celebrado en diciembre de 2002, Cunchillos (2003: 21) comenzaba su conferencia advirtiendo:

Es un hecho generalmente admitido que el Modernismo literario inglés se sustenta sobre cuatro pilares que se corresponden con cada uno de los miembros de lo que, en palabras del propio Lewis (1982a), constituyó

\footnotetext{
${ }^{10}$ Tesis monográficas sobre Lewis en la base de datos de la Biblioteca Británica. http:// ethos.bl.uk/SearchResults.do [Acceso 10/01/2015].

${ }^{11}$ El primero de ellos, “Aproximación semiótica a la obra narrativa de Percy Wyndham Lewis", dirigido por Pilar Alonso Rodríguez, lo presentó José María Ortiz Martínez en la Universidad de Salamanca en mayo de 1994. El segundo de ellos es "Intercambio de Recursos en la Ficción de Percy Wyndham Lewis”, de Melania Terrazas Gallego, que fue dirigida por Carmelo Cunchillos Jaime, y se defendió en la Universidad de La Rioja en diciembre de 2001. Por otra parte, las tesis en lengua inglesa consultadas suelen centrarse en una o dos obras del escritor o bien en un periodo determinado entre los muchos que atravesó el autor.

${ }^{12} \mathrm{La}$ aparición de este artículo es crucial y no ha recibido toda la atención que merece. Con la excepción de los trabajos generados por el grupo de investigación de La Rioja, muchas de las aportaciones de autores españoles no han sido recogidas en trabajos de especialistas de Inglaterra y Estados Unidos, por lo que sigue habiendo una brecha en las labores de investigación de autores de distintos países que, aunque publican en lengua inglesa, no realizan su labor investigadora en instituciones educativas del ámbito anglo-norteamericano. El título del artículo de Díaz Cuesta anticipa, además, la extensa monografía publicada por Edwards en 2000.
} 
"The Men of 1914": Ezra Pound, Percy Wyndham Lewis, T. S. Eliot y James Joyce.

La exposición sobre Lewis en la Fundación Juan March, primera retrospectiva desde la que realizó Tate un año antes de su muerte en 1956, fue el primer paso para divulgar su figura en sus facetas de escritor y artista. Su repercusión fue tal que recibió alabanzas por parte de la prensa británica, que, por lo general, no dedica demasiado espacio a un artista que ha sufrido el desprecio en su propio país ni a exposiciones de vanguardistas comisariadas en otros países.

En una reseña para The Independent del 8 de marzo de 2010, Tom Lubbock señalaba la relevancia de esta retrospectiva y, más importante aún, el "silencio atronador" que el autor había padecido durante décadas:

At the Fundación Juan March, until the middle of May, you can see the retrospective that Britain has never managed to get together. [...] The March Foundation is a vastly endowed private cultural institution, roughly a Spanish Guggenheim, for which there is no British equivalent. It has a curator who took a fancy to Lewis. So, they're having a show, which offers to break "the thundering silence".

And it is the show ${ }^{13}$.

La muestra fue la más amplia y exhaustiva que se le haya dedicado a Lewis en sus diferentes facetas. Contó con una asistencia de 36.982 visitas $^{14}$, una cifra más que excepcional, especialmente si se tiene en cuenta que Lewis es un escritor y artista apenas conocido entre el público español, poco estudiado en la Universidad y apenas accesible para los lectores por la escasez de traducciones y la dificultad de conseguir muchas de sus obras en lengua inglesa.

En la prensa española la figura de Lewis despertó diversas reacciones, todas ellas divididas entre su talento como pintor y sus simpatías por el fascismo. Documentadas sin demasiada precisión cronológica

\footnotetext{
${ }^{13}$ Lubbock, Tom. 2010. "Wyndham Lewis 1882-1957: Fundación Juan March, Madrid". http://tomlubbock.com/downloads/new/Wyndham_Lewis.pdf [Acceso 05/01 2015]. Comisarios de la exposición: Manuel Fontán del Junco y María Zozaya. Comisario invitado: Paul Edwards. Asesores especiales externos: Richard Humphreys y Yolanda Morató.

${ }^{14}$ Dato proporcionado por la Fundación Juan March en correspondencia personal.
} 
en varios medios de comunicación de tirada nacional (El País, La Vanguardia, $A B C$ y El Mundo), propiciaron cierto debate sobre sus aportaciones al arte y a la literatura de la primera mitad del siglo XX. A esta gran retrospectiva siguieron proyectos internacionales mucho más modestos, como la muestra itinerante "The Vorticists: Rebel Artists in London and New York, 1914-18” (2010-2011) ${ }^{15}$.

\section{Traducciones}

Durante la primera década del siglo XXI, han aparecido en España las traducciones de cuatro de sus obras, entre ellas, la del primer número de la revista Blast (1914), fruto de una exposición de la obra completa del autor, "Wyndham Lewis (1882-1957)", que, como se ha explicado, se llevó a cabo en la sede madrileña de la Fundación Juan March entre febrero y mayo de 2010. Pero la primera traducción en salir al mercado editorial fue la de The Revenge for Love, obra de Miguel Temprano y publicada al español con el título de Dobles fondos por el sello Alfaguara.

Aunque hubo otras propuestas editoriales anteriores para que las obras de Lewis vieran la luz en España, fue Dobles fondos la primera en lograr su propósito. Las fechas y el argumento de la obra desvelan el porqué. Teniendo en cuenta el resurgimiento del tema de la Guerra Civil en el año previo a la conmemoración de los ochenta años desde su fin, habría resultado extraño que la propuesta de traducción de una novela sobre el conflicto español escrita por un autor inglés tan importante para el modernismo británico no fuera aceptada por ninguna editorial. Cunchillos (2003: 25) había observado unos años antes:

Nadie prácticamente ha dedicado su labor al estudio de la visión que $\mathrm{P}$. W. Lewis tuvo de la España de la guerra civil y de la postguerra y, a través de brigadistas intelectuales, de su implicación en el conflicto cuando éste se extendió más allá de los Pirineos. [...] Puede y debe realizarse un estudio sobre Wyndham Lewis y su relación con los escritores (de

${ }^{15}$ La primera parada fue The Nasher Museum of Art en la Universidad de Duke (30/9/2010-2/1/2011). Más tarde viajó a la Peggy Guggenheim Collection, en Venecia (29/1-15/5/2011), y, finalmente, a la Tate Britain, esta vez con un título distinto: "The Vorticists: Manifesto for a Modern World" (14/6-4/9/2011). 
izquierdas) que escribieron sobre el conflicto español entre 1934 y 1939 (1937 es la fecha de edición de Revenge for Love).

Aunque tampoco recibió la esperada atención, esta primera traducción de una obra completa de Lewis marca un momento importante en la divulgación de su narrativa en España. Hasta entonces, solo había habido esfuerzos parciales, todos ellos destinados a ofrecer en español fragmentos del manifiesto vorticista o de la autobiografía del autor (Torre, 1965; Power, 1980; de la Iglesia, 1987; Morató, 2002). La segunda traducción completa llegaría con la edición semifacsímil del primer número de la revista Blast. La edición, que cuenta con un posfacio de Edwards, un artículo sobre los perfiles de los vorticistas a cargo de Power y una nota de Fontán del Junco, lleva como anexo a la traducción un "manual de uso", que actúa como cuerpo de anotación a las aproximadamente doscientas glosas que desentrañan los entresijos de un texto culturalmente oscuro un siglo más tarde, tanto en español como en inglés.

Debe señalarse que no todos los esfuerzos realizados en España, donde ha habido un rescate importante de la figura de Lewis, han tenido su reflejo en las investigaciones que se realizan en países de lengua inglesa. Con ocasión del centenario de la revista, se celebró un congreso internacional, BLAST 2014, en la Universidad de Bath Spa. Una de las ponencias, con el título "How to Annotate $B L A S T$ ", ${ }^{16}$ analizaba las enormes dificultades que conllevaría la toma de decisiones para-como anunciaba el título de la charla- anotar una revista de estas características, teniendo en cuenta que, en palabras del ponente, iba a ser la primera vez que se hacía. Como es obvio, el ponente desconocía el contenido de la edición española de Blast. Muy interesado se mostró el profesor a cargo de la próxima edición que formará parte de las obras completas de Lewis en Oxford University Press.

Mejor suerte que estas dos traducciones ha corrido la primera autobiografía de Lewis, Estallidos y bombardeos (Blasting and Bombardiering), publicada en español por Impedimenta en 2008. Ese mismo año, tanto la editorial como la traducción resultaron galardonadas. Impedi-

\footnotetext{
${ }^{16}$ Se celebró del 24 al 26 de julio de 2014 en Bath Spa University, institución donde trabajó Paul Edwards y realiza ahora su tesis uno de sus organizadores, Christopher Lewis, quien asistió a la inauguración de "Wyndham Lewis (1882-1957)" en Madrid. La ponencia citada, a cargo del profesor estadounidense Stephen Sturgeon, se presentó en el panel 8, que llevaba por título Making \& Annotating BLAST 1914/2014.
} 
menta, con su grupo Contexto, recibió el Premio Nacional a la Mejor Labor Editorial Cultural; la versión española del texto, con un aparato crítico de 480 notas, un prólogo y una introducción, obtuvo el Premio de Traducción de AEDEAN.

\section{Conclusiones}

A lo largo de su carrera como escritor y pintor, Lewis fue un blanco frecuente de la censura en Inglaterra y Estados Unidos. En España, fue prácticamente ignorado. Sin embargo, los primeros años del siglo XXI parecen anunciar que la situación cambiará en planos muy distintos. Ya en aquella conferencia de finales de 2002, Cunchillos (2003: 23) concluía que "[e]n los últimos años, no obstante, se está dedicando a Percy Wyndham Lewis, por parte de críticos y académicos, el esfuerzo y la dedicación que su obra merece".

La exposición sobre Wyndham Lewis en la Fundación Juan March marcó un antes y un después en las percepciones acerca del autor en España y logró atraer buenas críticas extranjeras. Las contadas traducciones de sus obras también han sido determinantes para dar a conocer a un escritor que había sido excluido sistemáticamente de los planes de estudio universitarios y los catálogos editoriales. El círculo censor parece cerrarse ahora que Oxford University Press ha decidido recuperar en la medida de lo posible todo lo perdido, encargando a Paul Edwards la edición de las obras completas del autor.

\section{Bibliografía}

Abellán, Miguel. 1980. Censura y creación literaria en España (1939-1976). Barcelona: Península.

Brighton, Andrew. 1996. Post-War Establishment Distaste for Wyndham Lewis: Some Origins. En Edwards, Paul (ed.) Volcanic Heaven. Essays on Wyndham Lewis's Painting and Writing. Santa Rosa: Black Sparrow Press, 169-83.

Cunchillos, Carmelo. 2003. Claves para una revaluación necesaria: Percy Wyndham Lewis, escritor y pintor. En Palacios, I.; López, M.; Fra, P. \& Seoane, E. (ed.) Fifty Years of English Studies in Spain. Actas del $X X V I$ Congreso de AEDEAN. Santiago de Compostela: U de Santiago de Compostela, 21-30. 
Edwards, Paul. 2000. Wyndham Lewis. Painter and Writer. New Haven, CT: Yale University Press.

Gardner, Helen Louise. 1972. Poems in the making: the first Gwilym James Memorial Lecture. Southampton: University of Southampton.

Lewis, Wyndham. 1977. Mrs. Dukes' Millions. Toronto: The Coach House.

Lewis, Wyndham. 1987. Reventador y bombardero. Calle Mayor 6: 33-54. [Traducción de Javier de la Iglesia].

Lewis, Wyndham. 2005. Dobles fondos. Madrid: Alfaguara. [Traducción de Miguel Temprano].

Lewis, Wyndham. 2008. Estallidos y bombardeos. Madrid: Impedimenta. [Traducción de Yolanda Morató].

Lewis, Wyndham. 2010. Blast $n .^{\circ}$ 1. Madrid: Fundación Juan March. [Edición, traducción y notas de Yolanda Morató].

Lewis, Wyndham. 2011. El dibujo del califa. Arquitectos, ¿dónde está vuestro vórtice? (1919). Estudio preliminar, edición y traducción. Sevilla: Universidad de Sevilla. [Traducción de Yolanda Morató (tesis)].

Lyall, Sarah. 1996 (23 de septiembre). 40 Poems That Eliot Wanted to Hide, Including Some on the Bawdy Side. The New York Times. http:// www.nytimes.com/1996/09/23/books/40-poems-that-eliot-wantedto-hide-including-some-on-the-bawdy-side.html?pagewanted $=$ all [Acceso: 03/01/2015].

Morató, Yolanda. 2002. Wyndham Lewis y la estética del inconformismo (tesina). Huelva: Universidad de Huelva.

Morató, Yolanda. 2011. Wyndham Lewis and the different forms of censorship. ES. Revista de Filología Inglesa 32: 225-239.

Moi, Ruben. 2009. Bordering Binarities and Cognitive Cartography: What on Earth Does Literature Have to do with Border Transactions? Nordlit 24: 53-64.

Power, Kevin. 1980. El Vorticismo. Poesía 9: 19-56.

Read, Forrest (ed.). 1967. Pound/Joyce. The Letters of Ezra Pound to James Joyce, with Pound's Critical Essays about Joyce. Nueva York: New Directions.

Rose, William K. (ed.). 1963. The Letters of Wyndham Lewis. Londres: Methuen.

Torre, Guillermo de. 1965. Historia de las Literaturas Europeas de Vanguardia. Madrid: Ediciones Guadarrama.

VV. AA. 2010. Wyndham Lewis (1882-1957). Madrid: Fundación Juan March. 
